\title{
A STUDY ON THERMAL DYNAMICS INSIDE CARLSBAD CAVERN, NEW MEXICO, USA
}

\author{
Andreas Pflitsch ${ }^{1, \mathrm{c}}$, Alexander Adam², Meike Schwabe ${ }^{2}$, Wilhelm Furian², and Stan Allison ${ }^{3}$
}

\begin{abstract}
The climatic conditions of Carlsbad Cavern, New Mexico, are particularly complex. Its variety of large, as well as very narrow chambers, tunnels, and remote areas is the reason for its diversity of microclimates and special climatic features that are the subject of this paper, which can be seen as accompanying the article "The importance of air temperature as a key parameter to identify climatic processes inside Carlsbad Cavern, New Mexico, USA" by Killing-Heinze et al. (this issue). Two studies measured the trends of temperature through much of the cave during March-April 2011 and February 2013. One of the studies also assessed airflow directions using puffs of smoke. The main result was the detection of the flow of cold outside air from the entrance down the floor of the Main Passage and into the Big Room, especially along its west side. Temperatures increased along the route from the entrance to the Big Room, but some locations in the Big Room showed temperature ranges as great as those in the Main Corridor.
\end{abstract}

\section{Introduction}

This paper, as well as the article "The importance of air temperature as a key parameter to identify climatic processes inside Carlsbad Cavern, New Mexico, USA" (Killing-Heinze et al., 2017 [this issue]), addresses the climatic conditions inside Carlsbad Cavern. Because the morphology and the climate of this cave system are extensively described in the other article, the authors will not give another introduction of the research area in this paper.

This paper relies on data and results of two independent studies (Schwabe, 2013; Adam, 2014) and aims at a better understanding of the temperature profile and the course of air currents inside the cave. This could be used to stop undesirable or negative impacts on the beauty of the cave or the bats that roost in the Left Hand Tunnel and Bat Cave sections of Carlsbad Cavern. This paper should add to the understanding of the cave's temperature regime by dealing with the following five questions: Which air temperatures and temperatures trends are measurable along the Main Corridor and inside the Big Room? Up to which point of the cave system is it possible to immediately track changes in the outside weather and how do these changes affect the different parts of the cave? Which airflow directions can be found inside the cave and how stable are they? Are there areas with increased wind velocity? Is it possible with the data available to draw conclusions on the prevailing thermal dynamic of Carlsbad Cavern?

For clarification of these questions, the results of two studies conducted in 2013 and 2014 were evaluated. In the course of the studies, measurements were conducted to assess the climatic conditions from the Natural Entrance to the Big Room. By using highly sensitive equipment, even small-scale changes of the air temperature could be detected. The results are presented and interpreted at first for each part of the cave individually and then for Carlsbad Cavern in its entirety.

\section{Methodology}

Both studies treated in this paper used data of the Bat Draw weather station of the Western Regional Climate Center located near the Carlsbad Caverns National Park Visitors Center to support their analysis and evaluation.

\section{Methods in Schwabe (2013)}

The equipment used during the period of measurement (March 9 to April 13, 2011) consisted of two TESTO 645 thermistors to measure the air temperature inside the cave, one TESTO Quicktemp 850-2 thermistor to measure the surface temperature, and one smoke wind indicator to visualize air currents. The TESTO 645 can measure the temperature with an accuracy of $\pm 0.1{ }^{\circ} \mathrm{C}$, whereas the TESTO Quicktemp 850 -2 has an accuracy of $\pm 1{ }^{\circ} \mathrm{C}$. During the measurements a yardstick was used as a mounting device for the TESTO 645.

The measurement route started at the amphitheater near the Natural Entrance and followed the descending tourist path down the switchbacks and through the Main Corridor to the Big Room Junction and then continued along the circular path around the Big Room. The measurement points are grouped and named by their position.

The outside measuring points $A_{s} 1$ to $A_{s} 12$ are arranged as centrally as possible along the asphalted switchbacks of the Natural Entrance to reduce the potential influence of the cave walls and their different topography (Fig. 1; the sub-

\footnotetext{
${ }^{1}$ Department of Geography, Ruhr-Universität Bochum, 44780 Bochum, GERMANY

${ }^{2}$ Department of Geography, Humboldt-Universität zu Berlin, 10099 Berlin, GERMANY

${ }^{3} 901 \mathrm{~N}$. Thomas Street, Carlsbad, NM 88220, USA

${ }^{\mathrm{C}}$ Corresponding Author: andreas.pflitsch@rub.de
} 
script $S$ is used to distinguish Schwabe's outside measuring points from Adam's). Measuring point $A_{s} 1$ is placed at the highest point of the descent, and therefore, is the farthest from the Natural Entrance. Point $A_{s} 12$ was located at the deepest point and lay almost inside the cave. $A_{s} 6$ to $A_{s} 12$ were already beneath the ceiling of the cave entrance. The inner measuring points MP1-50 were placed along the tourist trail and cover the area of the Main Corridor and the Big Room (Fig. 2). To complement the measurement program with a cross profile of the cave, supplementary measuring points (P1-P7) were placed close to the Devil's Spring at a large breakdown pile that can be found there (Fig. 3).

Because during the study questions arose about the origin of some air currents in the front part of the cave, the measurement program was extended on March 21, 2011, by eight additional measuring points, and the numbering of the original points was changed to accommodate them. Four of these were positioned on the main tourist path (MP0, 1.5, 3, and 8), while the others are located a little apart (MP4, 5, 6, and 7) (Figs. 2 and 4).

The data acquisition started on March 9 and ended on April 13, 2011. The first measuring traverse of the day (MG1) commenced at 4:30 a.m. local time (UTC-7), or 5:30 after the switch to summer time, and covered the outside locations AS1-AS12 followed by the measuring points MP1 and MP2, the additional points in the range

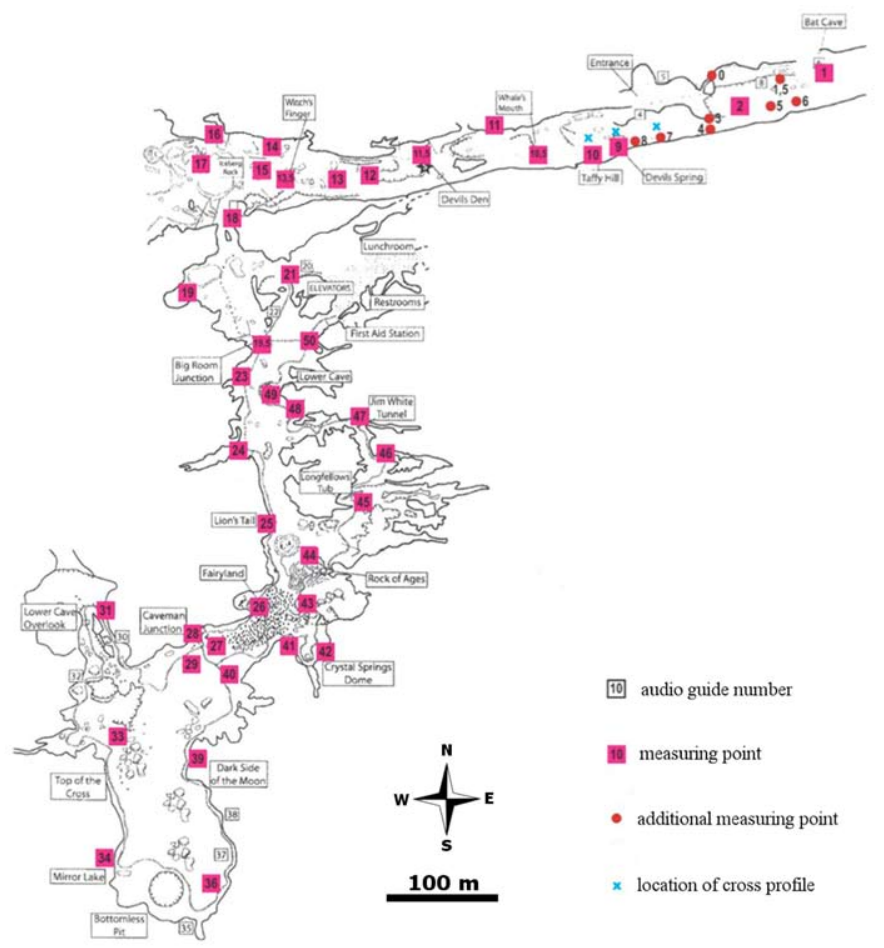

Figure 2. Plan of the main tourist part of Carlsbad Cavern showing the location of measuring points used by Schwabe (2013). The measuring points, both original and additional, are referred to in the text as MPn. The cross-profile was assessed by measuring points P1-P7. Most of the points are named for numbered stations in the audio guide to the cave supplied to visitors, although not all such stations were used.

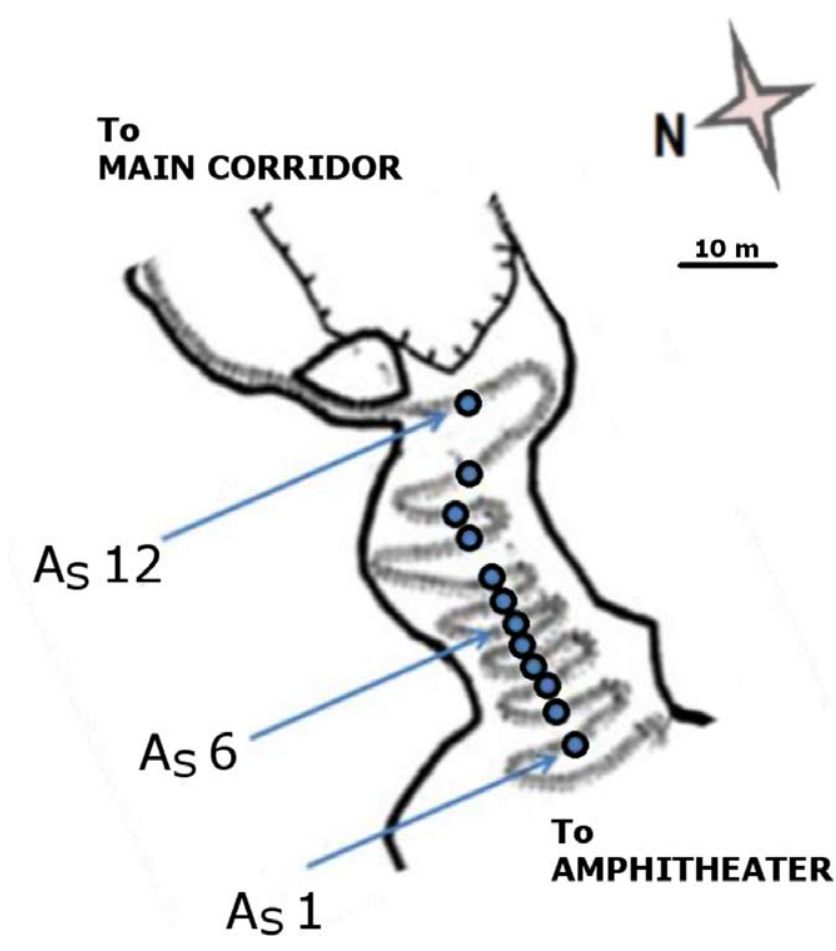

Figure 1. Positions of the outside measuring points $A_{s} 1-A_{s} 12$ in the area of the Natural Entrance of Carlsbad Cavern during Schwabe's study (Schwabe, 2013).

MP0-MP8, the measuring points of the cross profile P1$\mathrm{P} 7$, and the measuring points MP9-50 along the Main Corridor and inside the Big Room. The duration of MG1 was approximately three and a half hours. The second measuring traverse (MG2) started at 4:30 p.m. local time (5:30 summer time) and covered only the outside locations AS1-AS12, the measuring points MP1 and MP2, the additional points MP0-MP8, and the measuring points of the cross profile P1-P7. This measuring cycle ended after approximately one and a half hours at P7 (Table 1).

For the outside locations $A_{s} 1-A_{s} 12$ and the measuring points MP0-50, data acquisition consisted of first measuring the air temperature at a height of $2 \mathrm{~m}( \pm 0.1 \mathrm{~m})$ and then, except at $A_{s} 1-A_{s} 12$, assessing the flow conditions of the air with the aid of the smoke wind indicator. The data acquisition at the respective measuring points was performed in the middle of the main tourist trail and across its course. To determine the air current, smoke was set free by pressing the small bellows of the smoke wind indicator several times at a height of $1.5 \mathrm{~m}$ to $2.0 \mathrm{~m}( \pm 0.1 \mathrm{~m})$. By observing the movement of the smoke, the wind direction could be ascertained for each location. Further, the wind velocity was evaluated qualitatively and assigned to one of three velocity categories: slow, fast, and turbulent/ gusty. Afterwards, the surface temperature of the floor and the ceiling was measured. At the profile measuring points $\mathrm{P} 1-\mathrm{P} 7$, the temperature was measured beginning at a height of $20 \mathrm{~cm}$ and ending at a height of $3 \mathrm{~m}$, with one measurement each $20 \mathrm{~cm}$ resulting in vertical profile at each of the locations across the passage. 


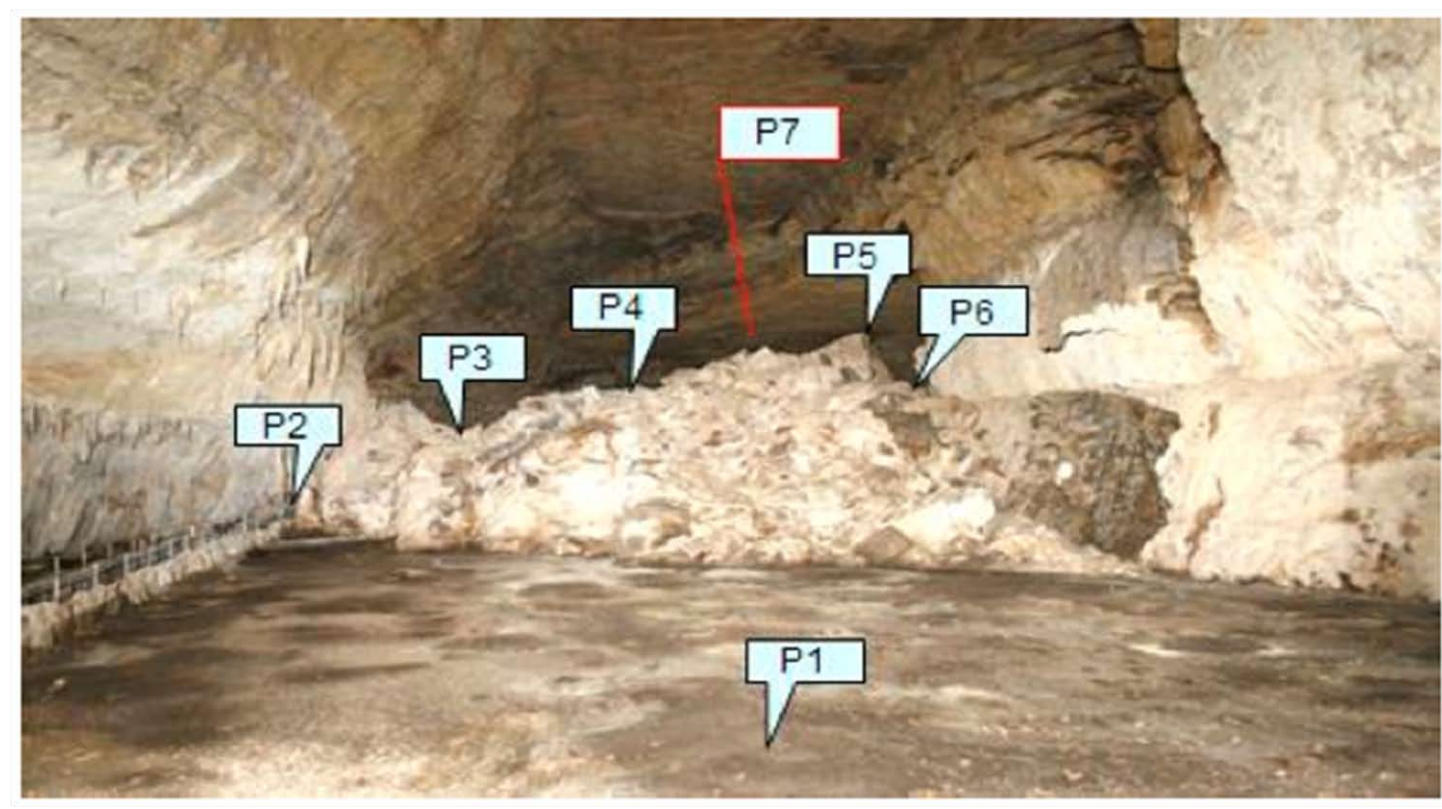

Figure 3. Positions of the measuring points $\mathrm{P} 1-\mathrm{P} 7$ of the cross section of Carlsbad Cavern, close to the Natural Entrance. P7 lies behind the rubble heap and cannot be seen in this photograph (Schwabe, 2013).

\section{Methods in Adam (2014)}

For the data acquisition, a TESTO 400 was used to measure the air temperature. Its two sensors cover a range from $-20{ }^{\circ} \mathrm{C}$ to $+70{ }^{\circ} \mathrm{C}$ with an accuracy of \pm 0.1 ${ }^{\circ} \mathrm{C}$. During the measuring cycles a yardstick was used as mounting device for the TESTO 400 and its temperature sensors were fixed at a height of $20 \mathrm{~cm}$ and $200 \mathrm{~cm}$.

During the week of February 6 to February 11 in 2013 each day's measuring cycles (MG1-MG4) were conducted every six hours, at 2 and 8 a.m. as well as 2 and 8 p.m. Every measuring cycle took approximately one and a half hours. This structure served two aims: to cover a spectrum of times as widespread as possible and to conduct the data acquisition with minimal disturbance to visitor traffic.

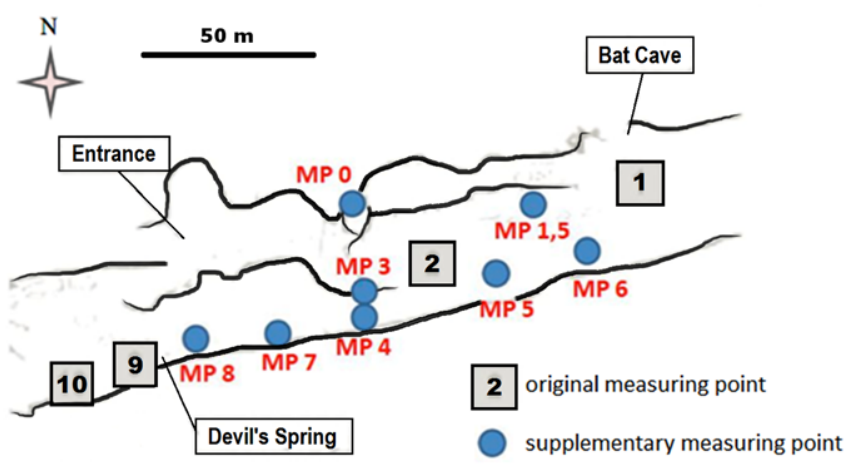

Figure 4. Location of the original measuring points MP1, 2, 9, and 10 and the later added points MP0, 1.5, and 2-8 in the front part of Carlsbad Cavern (based on Schwabe, 2013).

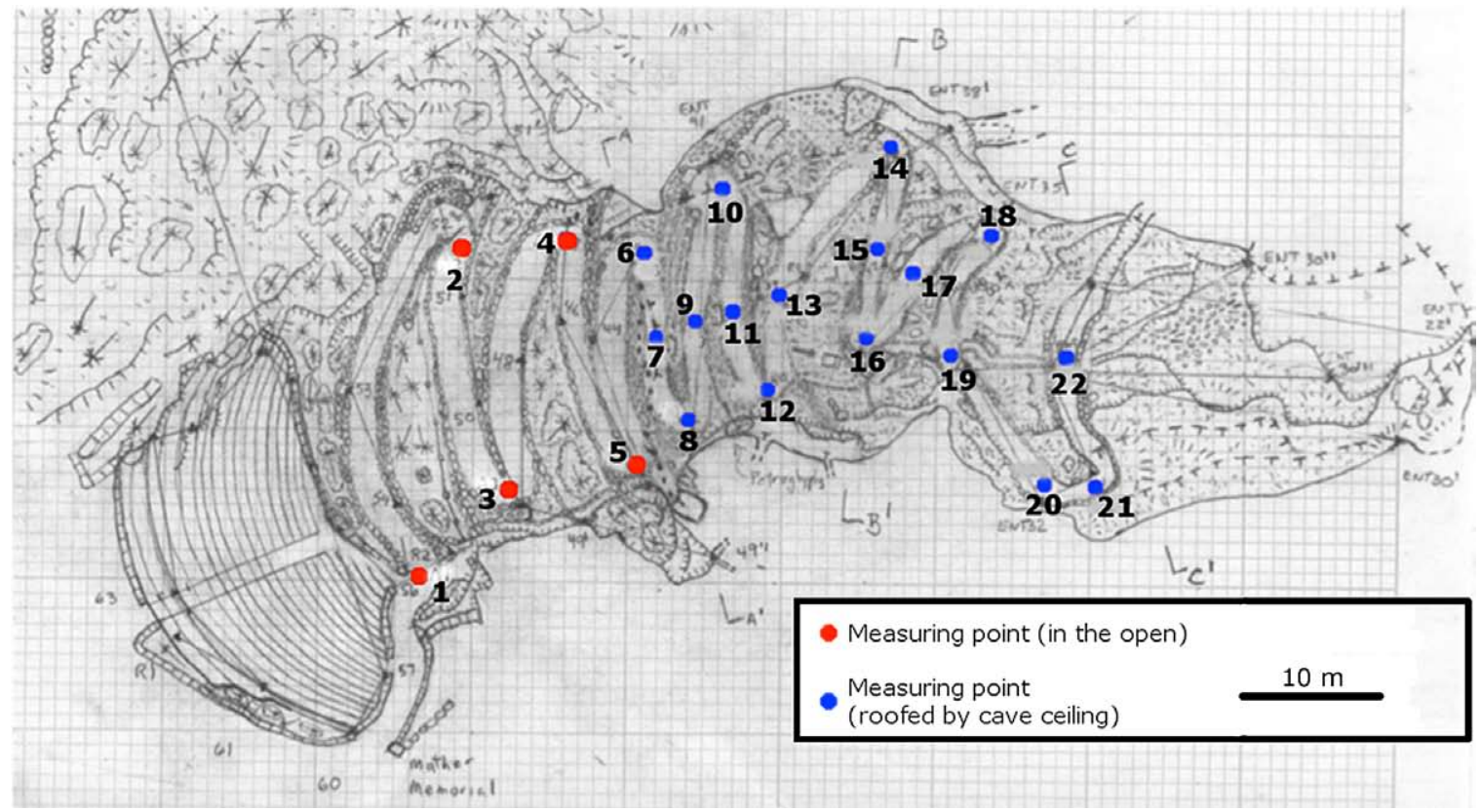

Figure 5. Positions of the outside measuring points $A_{A} 1-A_{A} 22$ in the area of the Natural Entrance of Carlsbad Cavern during Adam's study (Adam, 2014). 
Table 1. Overview on the position, the label and the number of the daily measuring cycles for all measuring points (based on Schwabe, 2013).

\begin{tabular}{|c|c|c|c|c|}
\hline Position & Original label & $\begin{array}{l}\text { Label adapted to } \\
\text { audio guide number }\end{array}$ & $\begin{array}{c}\text { Measuring cycle } \\
\text { (MG) }\end{array}$ & Special features \\
\hline Outside, cave entrance & $\mathrm{A} 1-\mathrm{A} 12$ & $\mathrm{~A} 1-\mathrm{A} 12$ & MG1+MG2 & Roofed $(\mathrm{A} 6-\mathrm{A} 12)$ \\
\hline Front section of cave & $2^{\text {nd }}$ gate & 0 & MG1+MG2 & Additional \\
\hline Front section of cave & Bat Cave & 1 & MG1+MG2 & $\cdots$ \\
\hline Front section of cave & Bat Cave/Guano pile & 1.5 & MG1+MG2 & Additional \\
\hline Front section of cave & Guano pile & 2 & $M G 1+M G 2$ & $\cdots$ \\
\hline Front section of cave & Next to Guano pile & 3 & MG1+MG2 & Additional \\
\hline Front section of cave & Apart from Guano pile & 4 & MG1+MG2 & Additional \\
\hline Front section of cave & Bat Cave $1^{\text {st }}$ rock (apart) & 5 & $M G 1+M G 2$ & Additional \\
\hline Front section of cave & Bat Cave $2^{\text {nd }}$ rock (apart) & 6 & MG1+MG2 & Additional \\
\hline Front section of cave & Trough (apart) & 7 & MG1+MG2 & Additional \\
\hline Front section of cave & Half way Devil's Spring & 8 & MG1+MG2 & Additional \\
\hline Front section of cave & Cross profile $1-7$ & $\mathrm{P} 1-\mathrm{P} 7$ & MG1+MG2 & Cross profile \\
\hline Main Corridor & $9-10$ & $9-10$ & MG1 & $\cdots$ \\
\hline Main Corridor & Whale's Mouth & 10.5 & MG1 & $\cdots$ \\
\hline Main Corridor & 11 & 11 & MG1 & $\cdots$ \\
\hline Main Corridor & $\mathrm{J} / \mathrm{K}$ & 11.5 & MG1 & $\cdots$ \\
\hline Main Corridor & $12-13$ & $12-13$ & MG1 & $\cdots$ \\
\hline Main Corridor & Witch's Finger & 13.5 & MG1 & $\cdots$ \\
\hline Main Corridor & $14-19$ & $14-19$ & MG1 & $\ldots$ \\
\hline Big Room & Intersection Big Room & 19.5 & MG1 & $\cdots$ \\
\hline Big Room & $21-50$ & $21-50$ & MG1 & $\cdots$ \\
\hline
\end{tabular}

With a length of approximately $2 \mathrm{~km}$ and an elevation difference of about $200 \mathrm{~m}$, the measurement route started at the amphitheater near the Natural Entrance and followed the asphalted switchback into the cave and then the course of the Main Corridor up to the Big Room Junction. Along this route, 45 measuring points are placed: $A_{A} 1-A_{A} 22$ outside and MP1-MP23 inside the cave.

The outside measuring points $A_{A} 1-A_{A} 22$ are spread across the asphalted switchbacks at the Natural Entrance; the subscript $A$ identifies Adam's outside points (Fig. 5). Like in the study of Schwabe (2013), $A_{A} 1$ is the highest point and the farthest from the entrance, while $A_{A} 22$ is the deepest and nearly inside the cave. While $A_{A} 1-A_{A} 5$ were placed at the northern and southern vertexes of the switchbacks, the measuring points $A_{A} 6-A_{A} 22$, which are covered by the ceiling of the entrance, were positioned at the vertexes, as well as the more central part of the entrance sink to cover the whole area of the switchbacks. The measuring points MP1-MP23 were placed along the Main Corridor leading downwards to the Big Room Junction (Fig. 6).

\section{Results and Discussion}

\section{The Outside Measuring Points and Devil's Spring}

The air temperatures at measuring point $A_{A} 1$, the farthest from the Natural Entrance (Fig. 5) showed a high correlation with the temperatures that were measured simultaneously at the BatDraw weather station; both showed strong fluctuations. Conversely, the air temperatures at the measuring point closest to the cave entrance $\left(A_{A} 22\right)$ were distinguished by relatively high thermal stability and reacted far more slowly to changes in the temperature of the outer atmosphere. The mean air temperatures of this measuring point showed only a small deviation during measuring cycles in the morning and in the evening compared to the much greater deviation at measuring point $A_{A} 1$. High temperature fluctuations at $A_{A} 22$ can be observed mainly during the morning measurements and are connected to cold air events, while the air temperatures during the evening measurements are very close to the mean temperature of the whole week. The contrast between $A_{A} 1$ and $A_{A} 22$ vanishes nearly completely as soon as the outside temperature approaches the mean temperature of $A_{A} 12$.

The sinking and varying influence of the solar radiation in the course of the switchback down to the Natural Entrance becomes clear in the mean air temperatures. The highest measuring points are the most exposed to sunlight, and 


\section{CARLSBAD CAVERN}

Main Corridor

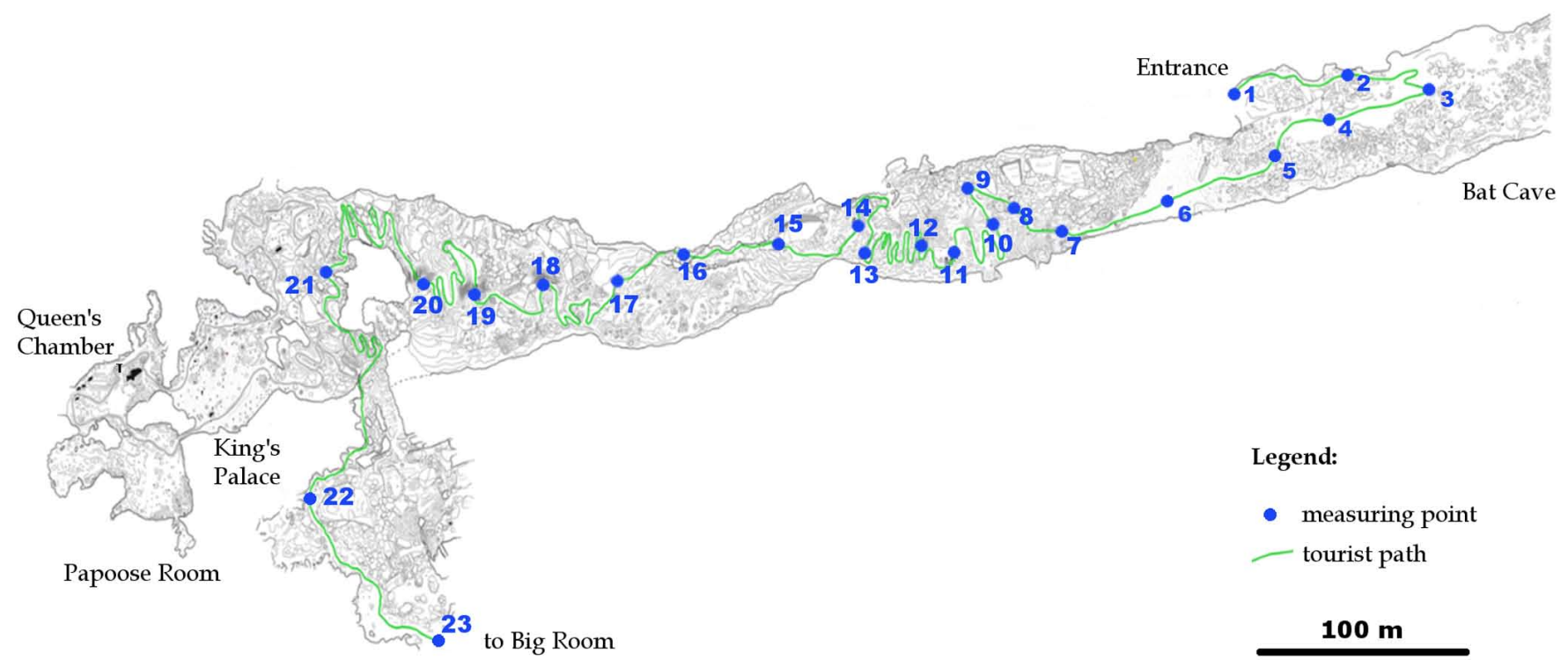

Figure 6. Positions of the 2013 measuring points MP1 - MP23 along the tourist route from the Natural Entrance to the start of the Big Room (based on Adam, 2014).

therefore, become the warmest during the day. The stronger and terraced decrease of the air temperatures from $A_{A} 6$ onwards can be ascribed to the shadowing by the ceiling of the cave entrance. In the evening, the ranges of the air temperatures are much more balanced in their scale, as well as in their course during the period of measurements than they are in the morning.

The outside measuring points of Schwabe (2013) (see Fig. 1) can be grouped into several temperature clusters (Fig. 7). To avoid the chaining of clusters, the complete-linkage method (CLINK) was employed for this step, also known as farthest neighbor clustering (Krebs, 1999). This agglomerative clustering technique uses a bottom-up approach, first combining similar elements to one cluster and then integrating similar clusters into bigger ones. For this, the crucial characteristic is the distance between those two elements in different clusters that are farthest away from each other. Where this distance is shortest two clusters are merged into one.

After the analysis of the characteristic course of the air temperatures during the morning measurements, four main clusters can be created (colored in Fig. 7a). The highest measuring points $A_{s} 1$ to $A_{s} 7$, most of which are not under the roof at the entrance, show very similar temperatures, and therefore, form the biggest cluster. A smaller cluster consists of the fully roofed measuring points $A_{s} 8$ to $A_{s} 11$, despite the fact that the air temperature is notably different at $A_{s} 11$ because of the lower ceiling there. Most conspicuous is the great similarity between $A_{s} 12$ and the inner measuring points MP1 and MP2. Because of this, $A_{s} 12$ forms a separate cluster that is more closely related to the cluster of the two inner points than to the other external points on the switchbacks. This exceptional status is caused by the strong influence of the cave atmosphere and by the lesser, but still existing, influence of the outer atmosphere, especially during cold air event.

For the evening measuring cycle, five main clusters can be found (colored in Fig. 7b) that differ distinctly from the ones of the morning cycle. Very similar are the air temperatures at the locations exposed to direct sunlight $A_{s} 1$ to $A_{s} 5$. The measuring points $A_{s} 6$ and $A_{s} 7$ that belonged to the same cluster during the morning cycle now form a separate cluster because of the shadowing influence of the cave entrance's ceiling. The cluster consisting of the measuring points $A_{s} 8$ to $A_{s} 11$ still exists, but with shifted similarities because of the different solar radiation. $A_{s} 12$ shows an even greater similarity to the inner measuring points, especially to MP1, that can be attributed to the similar elevation of the two locations. The most noticeable pattern is a cold air tongue that starts at the front part of the Natural Entrance and flows in direct line of sight down to and around MP2, which is located close to large pile of bat guano several meters lower than the measuring points $A_{s} 12$ and MP1. From there the colder air moves near the ground in the directions of both the Bat Cave and the Main Corridor. The measuring point MP2 is hardly influenced by the warming of the outer air during the day. The resulting temperature differences between MP2 and both $A_{s} 12$ and MP1 are reflected in the creation of an independent cluster for MP2. 


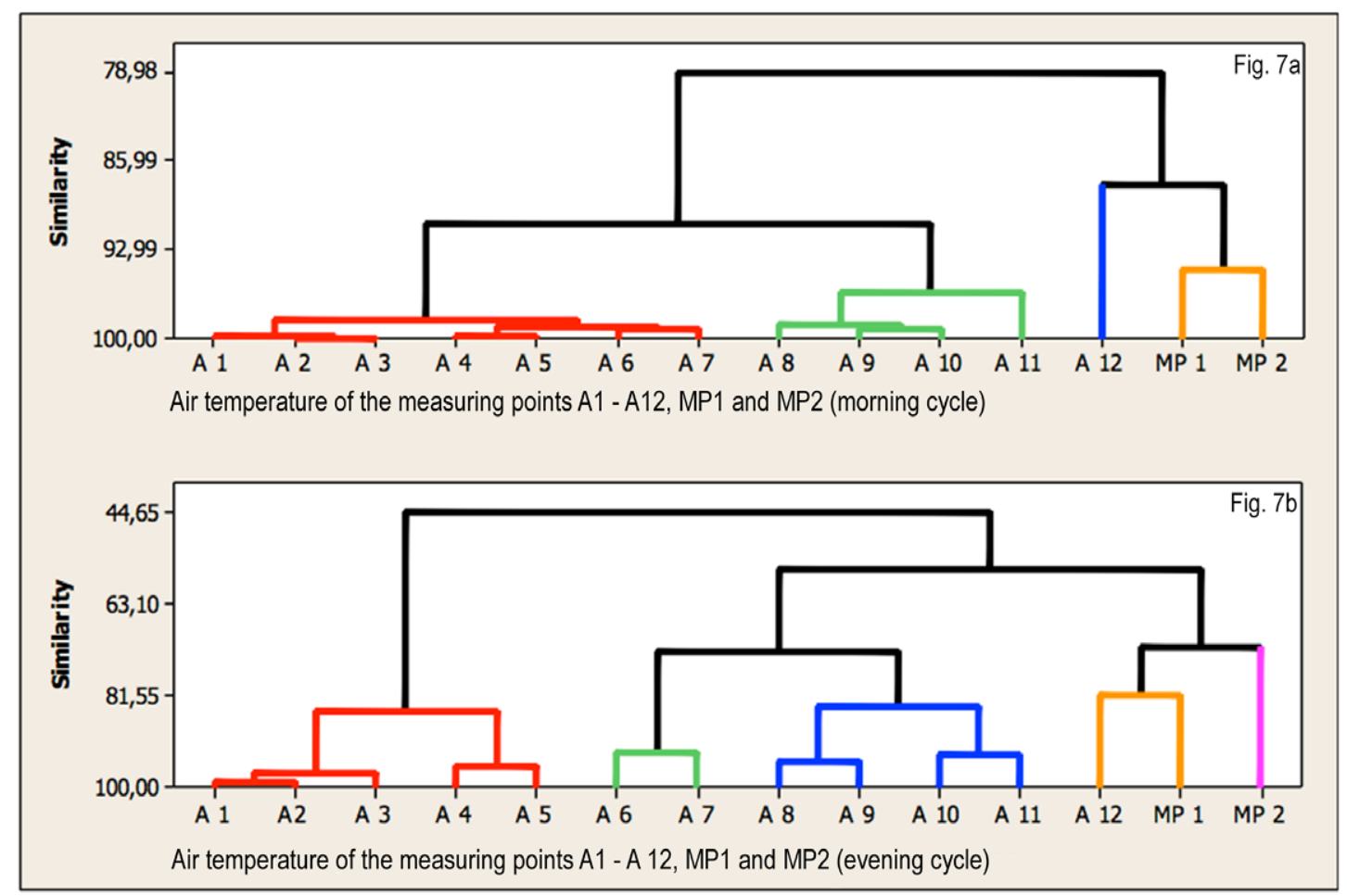

Figure 7. Results of the cluster analysis (complete linkage-method) for the air temperatures of Schwabe's measuring points $A_{s} 1-A_{s} 12, M P 1$, and MP2 as a dendrogram for the morning (Fig. 7a) and the evening (Fig. 7b) measuring cycles (based on Schwabe, 2013).

With the aid of the cross cross-section data provided by P1-P7 the origin of the air currents flowing in the direction of the Main Corridor can be determined. Two flow paths can be conjectured (Figs. 8a and b). In the first version, the inflow of air is completely on the left side of the guano pile beneath the cave entrance and does not expand to the right side of the cave until just ahead of the breakdown pile (Fig. 8a). The second possibility would be that only the main part of the inflowing air moves around the left side of the guano pile, while a small amount flows over it at the right and then down to the Main Corridor (Fig. 8b). Consideration of the seven locations in the cross-section illustrates the complex streaming and temperature patterns possible in this small part of the cave and gives an impression of the general prevailing circulation system inside Carlsbad Cavern during the measuring period.

\section{Main Corridor}

With increasing distance from the Natural Entrance, an overview of the measuring points clearly show a zoned structure with increasing air temperatures and decreasing temperature differences. The lowest temperatures were measured at the point closest to the entrance, while the highest temperatures belonged to a point in the Big Room level that is the farthest from the entrance. The increase in the air temperature shows a cascading course and can be attributed to a combination of the declining influence of the outside weather, the sloping Main Corridor, and the three dimensional shape of the cave.
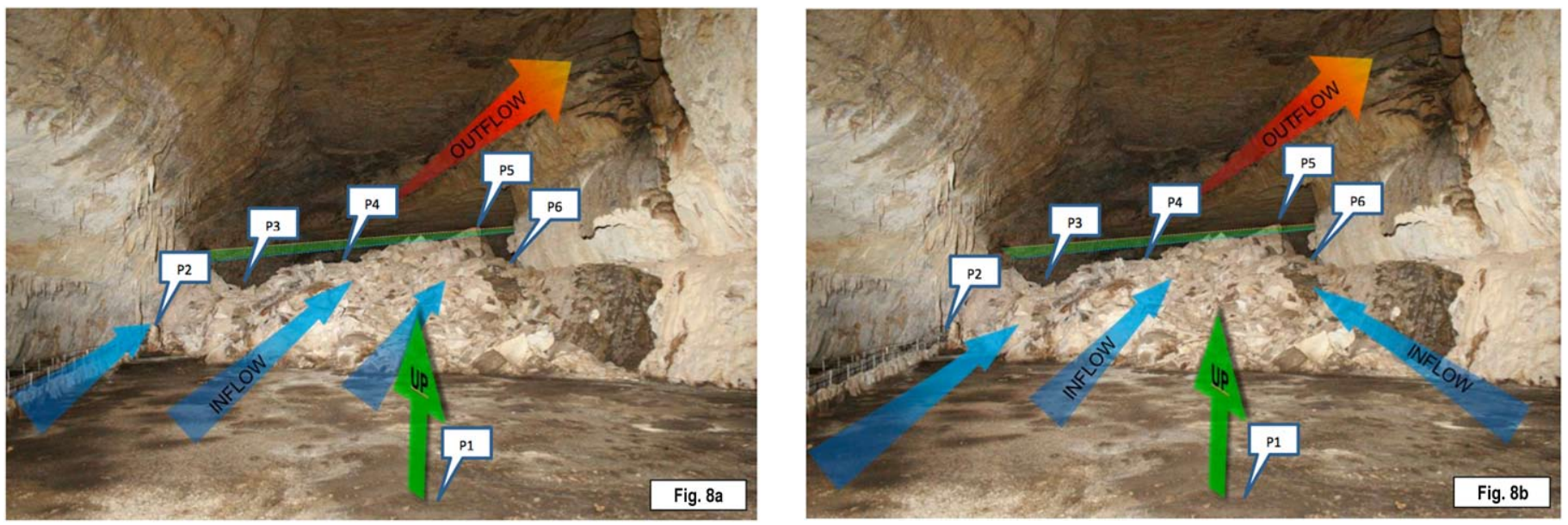

Figure 8. Alternative models of the airflow past the rubble heap at Devil's Spring that were investigated using the profile stations P1-P6. The second model (8.b) adds flow over the right side of the obstruction (Schwabe, 2013). 
The strong impact of the near-ground inflow from Natural Entrance and the Bat Cave through the Main Corridor on the air temperature at the measuring points in the Main Corridor starts behind the constriction at Adam's point MP7 that is caused by the breakdown pile near Devil's Spring. The increased velocity of the air, accompanied by a certain drift to the left side of the Main Corridor, was noticeable. Beyond the constriction the air currents move through a breach in a low rock formation and flow into a lower level close to MP10 (Fig. 9). As a result the profiles of the air temperature at MP8 and MP10 were quite similar, while at MP9, which is located away from the direct flow path, higher air temperatures could be measured during all measuring cycles.

According to Schwabe's data from 2011, increased velocity of the air currents is present up to the Witch's Finger formation, but suddenly not at the next measuring point, close to the Iceberg Rock, even though these two form a straight line (Fig. 2). The reduction of the air velocity can be explained by the strong blocking effect of a limestone formation directly behind the measuring point. Because of this formation, most of the inflowing air is led off to the right near Witch's Finger with further reduced velocity. The slower moving air then forms vertical currents in the following part of the cave (Fig. 10).

\section{Big Room}

Schwabe's measuring points inside the Big Room are located approximately $230 \mathrm{~m}$ beneath the surface and at least $1.8 \mathrm{~km}$ away from the Natural Entrance representing the deepest study locations. Considering their great depth below ground level and distance from the cave entrance, the measuring points of the Big Room show relatively high temperature fluctuations, both individually and in comparison to the others.

Figure 11 shows that the air temperature at a measuring point was lower the closer it was located to the junction of the Main Corridor and the Big Room, reflecting the influence of the cold inflow that is still present at this depth. Also the points nearer the entrance in general showed the greatest ranges of air temperature $\left(>0.8^{\circ} \mathrm{C}\right)$.

Deeper inside the Big Room, the air temperature increased, whereas its range decreased, underlining the declining influence of the air currents flowing down from the Main Corridor. Nevertheless, a certain shifting of the cooler measuring points was noticeable: Although all were colder the closer they were to the junction, the area of colder measuring points reached farther into the Big Room on the west side of the room (MPs in the twenties), which is more exposed to direct air flow from the Main Corridor.

Overall, in the Big Room only small fluctuations of the mean temperatures were visible when comparing the separate days; the outside weather could hardly can be detected inside the Big Room. Cold air events were visible with a one-day delay, but disappeared as time went on.

The air currents streaming through the Main Corridor fanned out broadly at the junction area. As mentioned above, the main part of the air seemed to flow into the Big Room on the western side. A small amount veered east in the direction of the elevators and the Lunch Room. The measuring points between the Big Room Junction and Lion's Tail were located on the main flow path of the air currents and were characterized by higher wind velocities. The other measuring points generally displayed slower and more likely vertical air currents (Fig. 12).

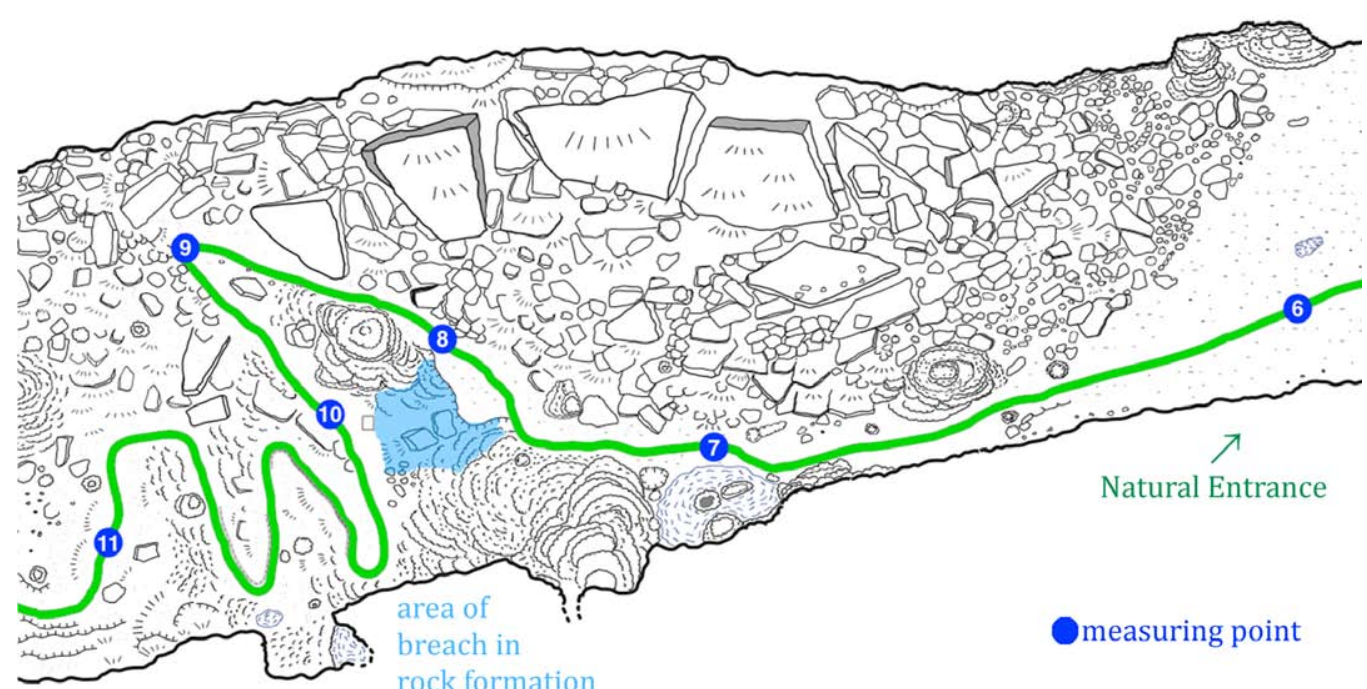

$\uparrow$

$\mathrm{N}$

rock formation

\section{Main Corridor}

$\longleftarrow$ Big Room
Figure 9. Map of the Main Corridor close to the Devil's Spring inside Carlsbad Cavern with the positions of Adam's measuring points MP6-MP11. The main airflow bypassed the tourist trail through the gap in the wall of formations (based on Adam, 2014). 
Figure 10. Depiction of the dominant air currents from the Natural Entrance through the Main Corridor to the Big Room according to the study in March-April 2011 (based on Schwabe, 2013). The relative velocity of the flow is coded in the thickness of the outline of the arrow.
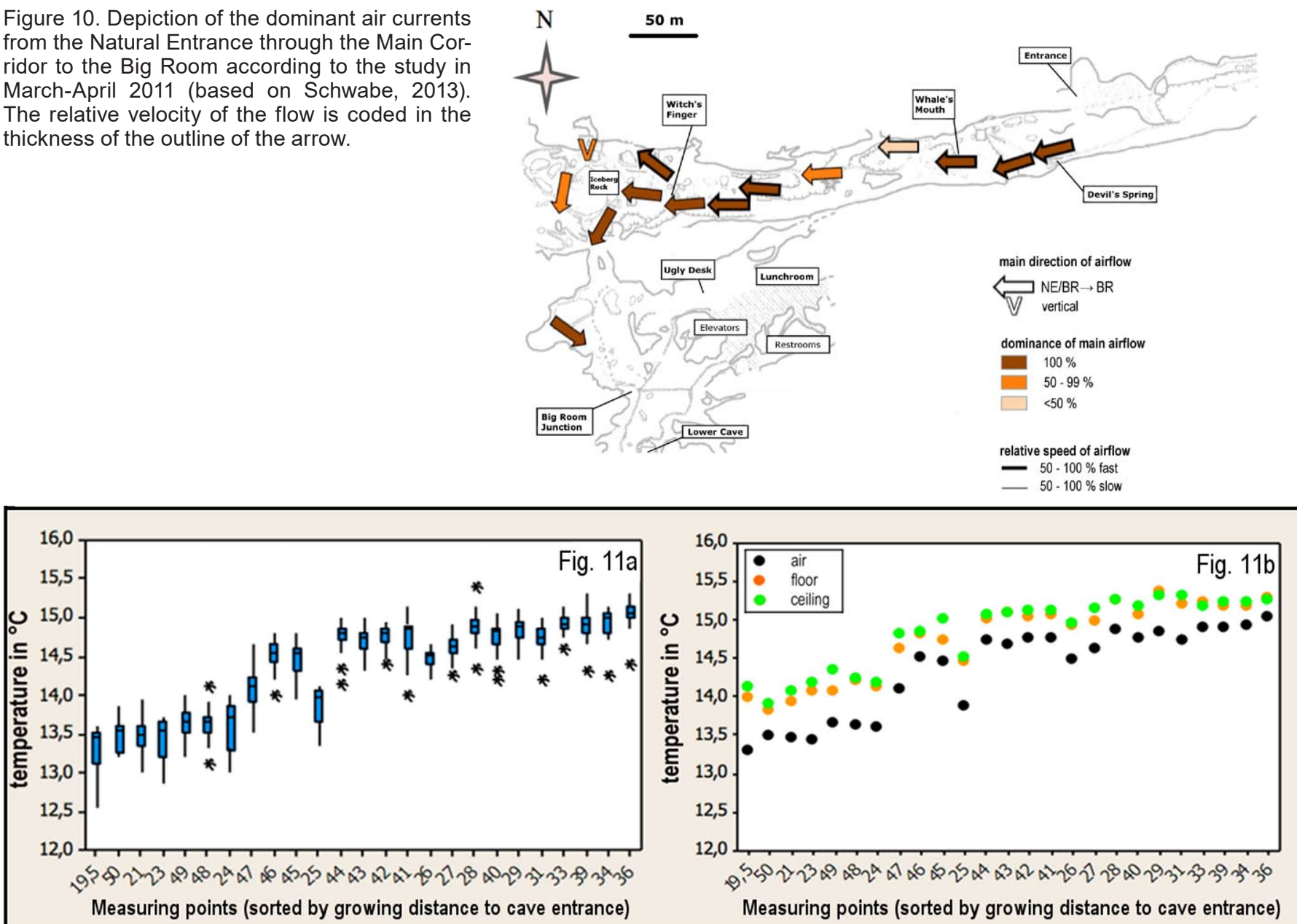

Figure 11. Air temperature ranges (box plot diagrams, part a) in the Big Room of Carlsbad Cavern for Schwabe's measuring points ordered by their distance from the Main Corridor and the cave entrance, as well as the mean temperature of the air and the rock surfaces (b) (based on Schwabe, 2013).

The inflowing air masses continued their course with the described western drift until the area around Caveman Junction. On the wet side of the Big Room, rock formations deflected inflowing air that then streamed into the back of the Big Room with an eastern drift. Near the Lower Cave Overlook, air currents were apparently rising from the Lower Cave into the Big Room. Most likely this air sank into Lower Cave along the ladder route near the start of the Big Room (Fig. 12). This cooler air would be warmed by the bedrock of the smaller passages in Lower Cave, which would explain the warm air rising from Lower Cave at the Lower Cave Overlook, more commonly referred to as the Jumping Off Place.

The most interesting measuring point was located in the rear part of the Big Room east of the Bottomless Pit (MP36). Despite its very deep position inside the cave and the great distance from the Main Corridor, it displayed the greatest variety of airflow directions. Vertical airflows dominate, but there are also air currents directed back into the Big Room.

To make room for the inflowing air there has to be an outflow of air. The air currents measured both at the more

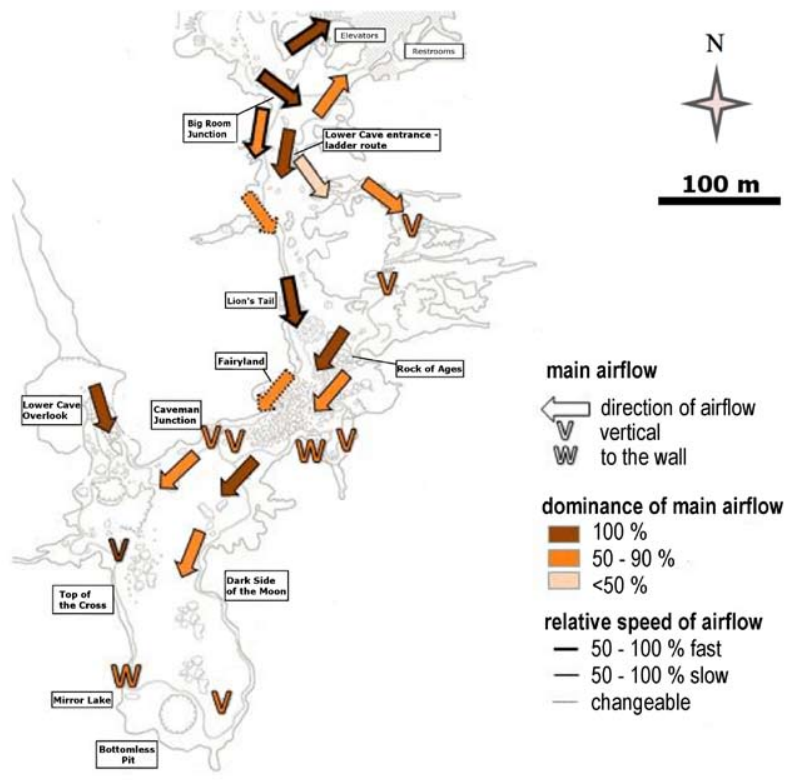

Figure 12. Depiction of the dominant airflow conditions at Schwabe's measuring points inside the Big Room, Carlsbad Cavern during March-April 2011 (based on Schwabe, 2013). The relative velocity is shown by the borders of the arrows. 


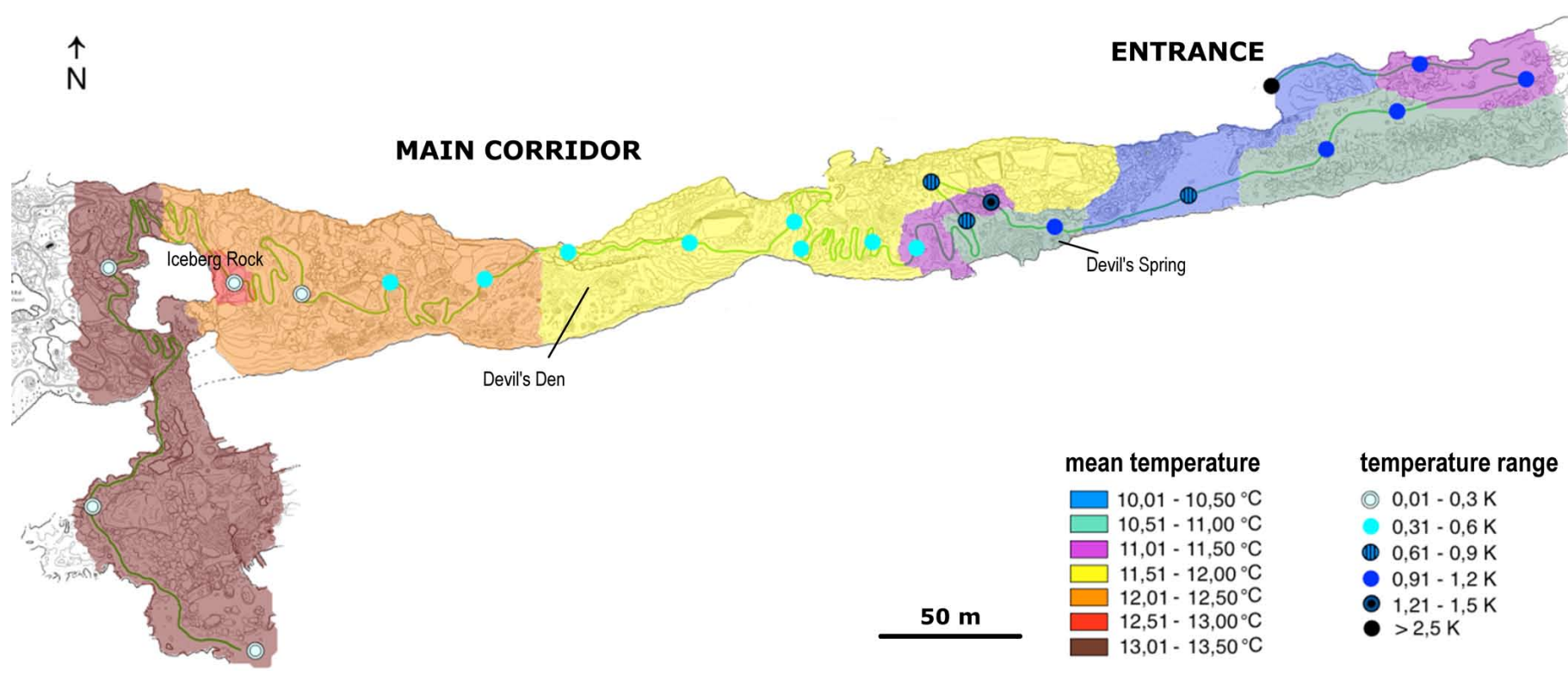

Figure 13. Depiction of the temperature conditions along the Main Corridor of Carlsbad Cavern by temperature zones (colored areas) and the temperature ranges at Adam's measuring points (circle icons) during February 2013 (based on Adam, 2014).

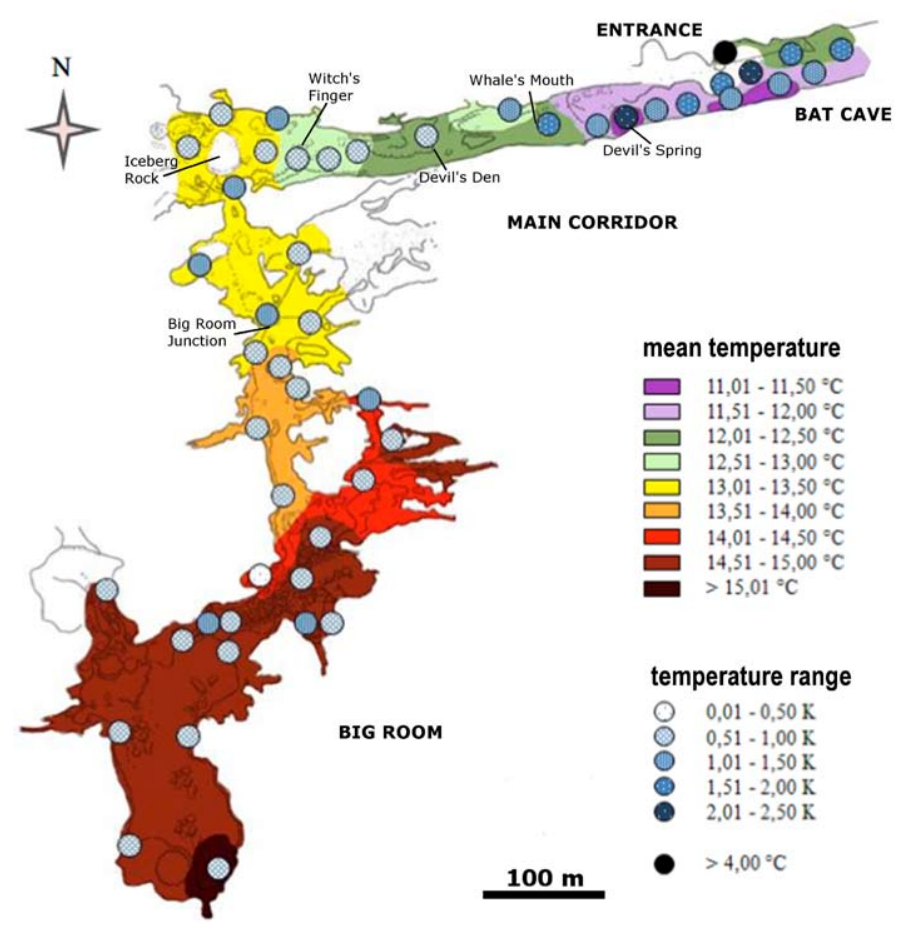

Figure 14. Depiction of the temperature conditions inside Carlsbad Cavern by temperature zones (colored areas) and the temperature ranges at Schwabe's measuring points (circle icons) in March-April 2011 (based on Schwabe, 2013).

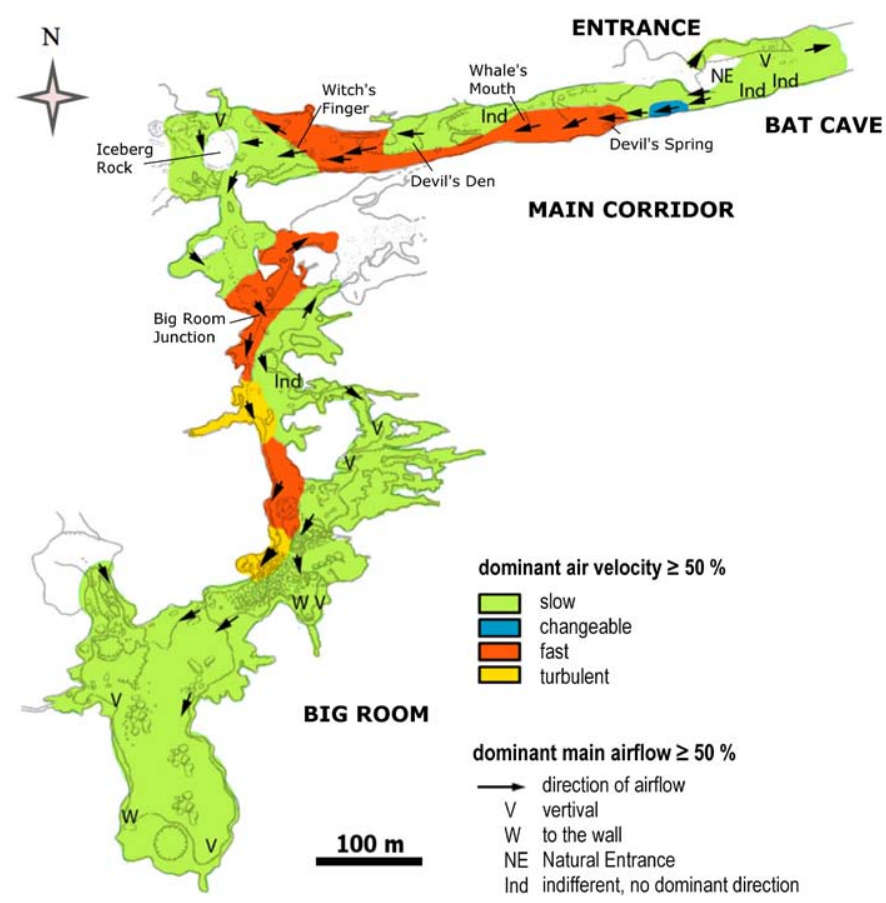

Figure 15. Depiction of the dominant airflow conditions (during at least $50 \%$ of the measurements) by using velocity zones (colored areas) and the dominant wind direction (arrows or letters) at Schwabe's measuring points inside Carlsbad Cavern during MarchApril 2011 (based on Schwabe, 2013).

sheltered locations and in the rear part of the Big Room could be an explanation for this phenomenon. The relatively warm air rises vertically and streams along the ceiling to the Main Corridor, which it then follows upward. Measuring the presumed warm air at the ceiling of the cave is logistically challenging due to the height of the Big Room and Main Corridor, which varies from $15 \mathrm{~m}$ to $70 \mathrm{~m}$, but most probably it is this air that forms the air currents observed at Devil's Spring streaming in the direction of the Natural Entrance and Bat Cave. 


\section{Summary}

By using the mean air temperatures and the mean air temperature ranges based on Adam's data (Fig. 13), and based on Schwabe's data (Fig 14), were created. Both show the mean temperatures as differently colored regions, as well as the temperature ranges at each measuring point in the form of a circle icon. The ranges show a distinct trend, with rising mean air temperatures coinciding with a decrease in the temperature ranges, but the front section of the cave paints a much more differentiated picture concerning the mean air temperatures than concerning their ranges. It displays the complex and changeable properties of the air temperature at the measuring points despite their spatial proximity.

Additionally, the average of each measuring point reflects its elevation, leading to increasing or decreasing air temperatures along the measuring route. Along the Main Corridor, the mean air temperatures and ranges of the measuring points after Devil's Spring show the strongest response to changes in the outside weather. Farther along the route deeper into the cave this response weakens until beyond the Iceberg Rock it is nothing more than a small fluctuation.

Air currents coming from the Main Corridor and flowing into the Big Room and their impact on their nearest surroundings are shown in Figure 14. Despite the fact that the measuring points inside the Big Room display much higher temperatures and are located very much farther from the entrance than the measuring points inside the Main Corridor, many of both belong to the same categories of temperature ranges. Especially surprising is the extent of the temperature differences (up to $1.5 \mathrm{~K}$ ) that were measured inside the Big Room.

In contrast to Figure 13, based on data taken in February, the mean air temperatures in Figure 14, based on data from March and April, are approximately $1^{\circ} \mathrm{C}$ higher, while the range of the air temperatures at some locations differs by $1.5 \mathrm{~K}$. This can be attributed first and foremost to the period of the data acquisition. It reflects different outside weather conditions and the increased air exchange between cave and free atmosphere during the transition from winter to spring. But despite the weather conditions outside the cave, the mean air temperatures inside approach each other with growing distance from the Natural Entrance until they reach a similar level in the area of the Iceberg Rock. Measurements by Adam and Schwabe resulted in slightly different absolute values (12.51-12.50 ${ }^{\circ} \mathrm{C}$ for Adam and $13.01-13.50$ ${ }^{\circ} \mathrm{C}$ for Schwabe). However, both Figure 13 and Figure 14 show the reduced fluctuations at this point of the cave. This shows on the one hand that at this point there is almost no response to the meteorological conditions outside the cave. On the other hand it emphasizes the appearance of the Big Room as cold trap or Eiskellertypus (ice-cellar type) after Trimmel (1968) and Furian (2014).

Regarding the wind velocity (Fig. 15) the front section of the cave, surprisingly, is an area of relatively slow speeds, but there is a small part away from the tourist path where elevated turbulences and gusts can be measured. Regardless of their slow or turbulent streaming properties, all measuring points display a variety of intertwining air currents, which is why a predominate wind direction could only be ascertained for a small number of locations in the front section (> 75\% of the measuring period). This emphasizes the vicissitude of the air circulation in this area. The air currents observed at Devil's Spring that seemingly originate in the Bat Cave continue their course deeper into the cave and can be measured at nearly all measuring points of the Main Corridor. In the Main Corridor two areas of increased wind speed stand out, directly after Devil's Spring and between Devil's Den and Witch's Finger. These are flanked by zones of slow velocities. The increased wind speed can be explained by the proximity to the entrance and by the constricted passage size of this section.

Other than the front part of the cave, the Big Room shows the most complex flow pattern. The air flowing out of the Main Corridor pours delta-shaped into the chamber at the Big Room Junction and continues its course with the described drift. These flow paths too are an area of increased and turbulent wind velocities. But this has to be seen as relative, because these faster air currents do not reach the speed of those close to the Natural Entrance. Nevertheless they clearly exceed the speed of the air currents at other measuring points in the Big Room. From the streaming patterns at some measuring points meaningful evidence can be deduced suggesting a permanent connection of the air movements between the Big Room and other cave sections such as the Lower Cave and the Left Hand Tunnel.

The collected data displayed general trends and specific characteristics for the surveyed periods of time, reflecting the complexity and vicissitude of the thermodynamic processes inside and outside the cave. But they merely are a snapshot in time, as they only can describe the condition of the cave climate during the measurement periods. Nevertheless, the results of previous studies could be confirmed and extended by new knowledge, thus forming a promising basis to build upon with future research. Through greater understanding of the temperature and streaming patterns inside the cave, consequences can be predicted that might affect the beauty of the cave.

\section{Acknowledgements}

The authors wish to thank the National Park Service rangers of Carlsbad Cavern for their valued support during the measurements of the two studies. We also wish to thank our reviewers for making valuable comments and improvements on an earlier version of this paper. 


\section{References}

Adam, A., 2014, Untersuchungen zur thermischen Dynamik innerhalb der Carlsbad Cavern, New Mexico, USA [bachelor thesis]: Humboldt-Universität zu Berlin.

Furian, W., 2014, Die Lufttemperatur als wichtige Leitgröße für die klimatischen Prozesse in der Carlsbad Cavern, New Mexico, USA [bachelor thesis]: Humboldt-Universität zu Berlin.

Killing-Heinze, M, Pflitsch, A., Furian, W., and Allison, S., 2017, The importance of air temperature as a key parameter to identify climatic processes inside Carlsbad Cavern, New Mexico, USA: Journal of Cave and Karst Studies, vol. 79, no. 3, (this issue).

Krebs, C.J., 1999, Ecological Methodology, second ed.: Menlo Park, Addison Wesley Longman, 624 p.

Schwabe, M., 2013, Untersuchungen zur thermischen Dynamik und zur Bewetterung der Carlsbad Caverns in New Mexico (USA) in Abhängigkeit vom äußeren Witterungsverlauf [diploma thesis]: Humboldt-Universität zu Berlin.

Trimmel, H., 1968, Höhlenkunde: Braunschweig, Vieweg-Verlag, 300 p. 